\title{
Analysis of alterations of WFDC1, a new putative tumour suppressor gene, in hepatocellular carcinoma
}

\author{
Raphaël Saffroy*,1, Philippe Riou ${ }^{1}$, Gwendoline Soler ${ }^{1}$, Daniel Azoulay ${ }^{2}$, \\ Jean-François Emile ${ }^{3}$, Brigitte Debuire ${ }^{1}$ and Antoinette Lemoine ${ }^{1}$
}

\begin{abstract}
${ }^{1}$ Service de Biochimie et Biologie moléculaire, Hôpital Universitaire Paul Brousse, UPRES 1596-Faculté de Médecine Paris-Sud, 14 avenue Paul Vaillant Couturier 94804 Villejuif Cedex, France; ${ }^{2}$ Centre Hépatobiliaire, Hôpital Universitaire Paul Brousse, UPRES 1596-Faculté de Médecine Paris-Sud, 14 avenue Paul Vaillant Couturier 94804 Villejuif Cedex, France; ${ }^{3}$ Service d'Anatomie pathologique, Hôpital Universitaire Paul Brousse, UPRES 1596-Faculté de Médecine Paris-Sud, 14 avenue Paul Vaillant Couturier 94804 Villejuif Cedex, France
\end{abstract}

\begin{abstract}
WFDC1 is a recently isolated human gene identified as a tumour suppressor gene candidate. It is not known whether alterations in this gene are associated with human cancers. The WFDC1 gene maps in human chromosome 16q24, an area of frequent loss of heterozygosity (LOH) in several tumour types, in particular in hepatocellular carcinoma (HCC). We investigated its role in 46 European HCC by means of the detection of LOH at the WFDC1 locus. We describe here an assay for the detection of loss of heterozygosity at this locus using two dinucleotide repeat polymorphisms identified in WFDC1 introns, with a combined informativity of $86 \%$. LOH was observed in 4/40 informative HCC samples. We further investigated the role of WFDC1 as a tumour suppressor gene candidate in five hepatocellular cell lines and in tumours exhibiting LOH by means of mutation, promoter methylation and gene expression analysis. In HCC samples showing LOH, no mutation of the remaining allele was observed. No significant up or down gene expression was observed in tumour samples comparatively to normal liver and gene expression did not seem related to promoter methylation. These results suggest a minor role, if any, of WFDC1 in hepatocarcinogenesis. However, this approach might be useful for investigating the role of this candidate tumour suppressor gene in other tumour types. European Journal of Human Genetics (2002) 10, 239 - 244. DOI: 10.1038/sj/ejhg/5200795
\end{abstract}

Keywords: WFDC1; LOH; 16q24; hepatocellular carcinoma

\section{Introduction}

Recently, a new human gene involved in carcinogenesis, WFDC1, was cloned and characterized. ${ }^{1}$ The WFDC1 gene encodes a protein named ps20. The rat homologue of ps20 was originally identified as a secreted growth inhibitor ${ }^{2,3}$ and was purified from the conditioned medium of a foetal rat urogenital sinus mesenchymal cell line. ${ }^{4}$ Amino acid

\footnotetext{
*Correspondence: Raphaël Saffroy, Service de Biochimie et Biologie moléculaire, Hôpital Paul Brousse, 14 avenue Paul Vaillant Couturier 94804 Villejuif Cedex, France. Tel: 331455969 03; Fax: 33145593625 E-mail: raphael.saffroy@pbr.ap-hop-paris.fr

Received 21 August 2001; revised 31 January 2002; accepted 4 February 2002
}

sequence analysis shows that ps20 contains a WAP-type four-disulphide core motif suggestive of a protease inhibitor. ${ }^{5}$ The rat ps20 exhibited growth inhibitory effects on tumour cell lines. ${ }^{5}$ These growth regulatory effects and the cell phenotypic properties in vitro, suggest that ps20 may function as a mediator of stromal-epithelial interactions and contribute to the maintenance of tissue homeostasis. ${ }^{6}$ The ps20 gene, WFDC1, is thus a putative tumour suppressor gene.

The human WFDC1 gene consists of seven exons and was mapped by fluorescent in situ hybridization (FISH) to $\mathrm{Chr}$ 16q24, less than $2 \mathrm{Mb}$ from the telomere. ${ }^{1}$ A BLASTN search against $\mathrm{nr}$ (the non redundant set of GenBank, EMBL and DDBJ database sequences) revealed that the chromosome 16 clone RP11-486L19 (GenBank accession no AC009123), 
contains WFDC1 cDNA sequences and confirmed that the WFDC1 gene maps to $16 \mathrm{q} 24.3$.

Chromosomal deletions at $16 \mathrm{q} 24$ have been associated with several human cancers, including hepatocellular carcinoma, ${ }^{7,8}$ prostate cancer, ${ }^{9}$ Wilms' tumour, ${ }^{10}$ breast cancer $^{11,12}$ and ovarian cancer. ${ }^{13}$ It is therefore likely that there are one or more tumour suppressor genes in the 16q24 area. WFDC1 may be one of these genes. There have been no studies of alterations at the WFDC1 locus in human cancers.

The inactivation of a tumour suppressor gene requires complete loss or inactivation of both alleles. This occurs generally by mutation of one allele and deletion of the other. This mechanism, initially proposed by Knudson for the retinoblastoma gene, ${ }^{14}$ has been confirmed for a large variety of genes. As a consequence, recurrent allelic losses of specific chromosomal regions in tumour cells have been taken as evidence for the presence in these regions of tumour suppressor genes that may be functionally inactivated by a two-hit process. Detection of loss of heterozygosity (LOH) at the WFDC1 locus may be very informative for investigating its role, if any, in tumour suppression. As a consequence, data on $\mathrm{LOH}$ for the WFDC1 locus may be more easily interpreted if a polymorphism at the WFDC1 locus is detected. In this paper we have identified two dinucleotide repeat polymorphisms at the human WFDC1 locus (WFDC1-GT20 and WFDC1-GT12) and used them to detect LOH in hepatocellular carcinomas. Furthermore, to precise the role of WFDC1 in hepatocarcinogenesis, we also screened the WFDC1 gene for mutations and the level of promoter methylation was assessed. Finally, we studied its expression in normal and tumoral liver samples, in isolated hepatocytes and in five hepatocellular carcinoma cell lines.

\section{Materials and methods}

\section{Tumour samples and cell lines}

Liver tissues were harvested during the course of surgery and kept embedded in paraffin. Histology was reexamined by the pathologist and samples containing more than $70 \%$ tumourous cells were selected. Five human liver tumor cell lines HepG2, PLC/PRF/C, TONG, HA22TNGH and MAHLAVU were also obtained from the American Type Culture Collection. Cells were grown in Dulbecco F12 RPMI-1640 medium (Life Technologies, Cergy Pontoise, France), containing 10\% FCS and gentamycine, and harvested at 70\% confluence. Human hepatocytes were isolated by collagenase digestion from normal livers from three cadaveric multiple organ donors, as previously reported. ${ }^{15}$

\section{LOH analysis}

Polymorphisms in the WFDC1 cDNA sequences were located by analysis of the sequence of the RP11-486L19 clone. WFDC1-GT20 was located between the fourth and fifth exons and WFDC1-GT12 between the third and fourth exons. To study WFDC1-GT20, primers were synthesized to give a final amplification product of $181 \mathrm{bp}$ (GT strand primer: 5'-CCTGTCTTCGTAAAGGGAGG-3'; AC strand primer: 5'-TCAAATCGTTCATTTGGGAG-3'). The GT strand PCR primer was labelled with HEX fluorescent dye (Eurogentec, Seraing, Belgium). WFDC1-GT12 was analysed by means of primers synthesized to give a final amplification product of 206 bp (GT strand primer: 5'-TGACTGTGTCCGCTAGAGTG3'; AC strand primer: 5'-TACGCACGCATCCCC-3'). The GT strand PCR primer was labelled with 6-FAM fluorescent dye. We conducted a BLASTN search to confirm the specificity of the nucleotide sequences chosen as amplification primers. PCR was performed in multiplex for the two polymorphisms in a $25 \mu \mathrm{l}$ volume containing $5 \mathrm{pmol}$ of each primer, $40 \mu \mathrm{M}$ each of deoxynucleotide triphosphate, standard PCR reaction buffer containing $1.5 \mathrm{mM} \mathrm{MgCl}_{2}$, and $1 \mathrm{U}$ Taq DNA polymerase (Q.biogene, Illkirch, France) using a GeneAmp PCR system 2400 (Applied Biosystems, Courtaboeuf, France). One $\mu \mathrm{l}$ of DNA extracted from formalin-fixed paraffin-embedded specimens of tumour tissue or $50 \mathrm{ng}$ of DNA extracted from paired peripheral blood samples obtained at distance from surgery was amplified. Amplification consisted of one cycle of $2 \mathrm{~min}$ at $94^{\circ} \mathrm{C}, 35$ cycles of $1 \mathrm{~min}$ at $92^{\circ} \mathrm{C}, 30 \mathrm{~s}$ at $55^{\circ} \mathrm{C}, 45 \mathrm{~s}$ at $72^{\circ} \mathrm{C}$ plus a final extension step of $7 \mathrm{~min}$ at $72^{\circ} \mathrm{C}$. One $\mu \mathrm{l}$ of the PCR products diluted in $25 \mu$ l final formamide were separated by capillary electrophoresis using an ABI PRISM 310 sequencer (Applied Biosystems, Courtaboeuf, France). LOH was quantitatively assessed by calculating the $\mathrm{LOH}$ index, which was defined as the allele ratio in the tumour tissue in comparison to the allele ratio in the normal control. The allele ratio was calculated as the peak height of the smaller allele divided by the peak height of the larger allele. If the LOH index was less than 0.5 or more than 2.0 , we defined the case as showing LOH.

Table 1 Primer sequence for exon-amplification

\begin{tabular}{lll}
\hline Target region & Forward $\left(5^{\prime} \rightarrow 3^{\prime}\right)$ & Reverse $\left(5^{\prime} \rightarrow 3^{\prime}\right)$ \\
\hline Exon 1 & GGACACATGATCCGAGGGAC of product \\
Exon $2 \mathrm{a}$ & AGGTGGCCCAGCTTTAAGCC & CCTCTCCTCAAGGCTGACTCC \\
Exon $2 \mathrm{~b}$ & GCGGGCAGCGGTCTG & CTGCTGACACCGCCCTCTC \\
Exon 3 & GGAGCCTCTGTGCTGTCATGA & 322bp \\
Exon 4 & CGTTCCCTGCACCCGTC & CCTGGCTCCTGCTTGCTGTT \\
\hline
\end{tabular}



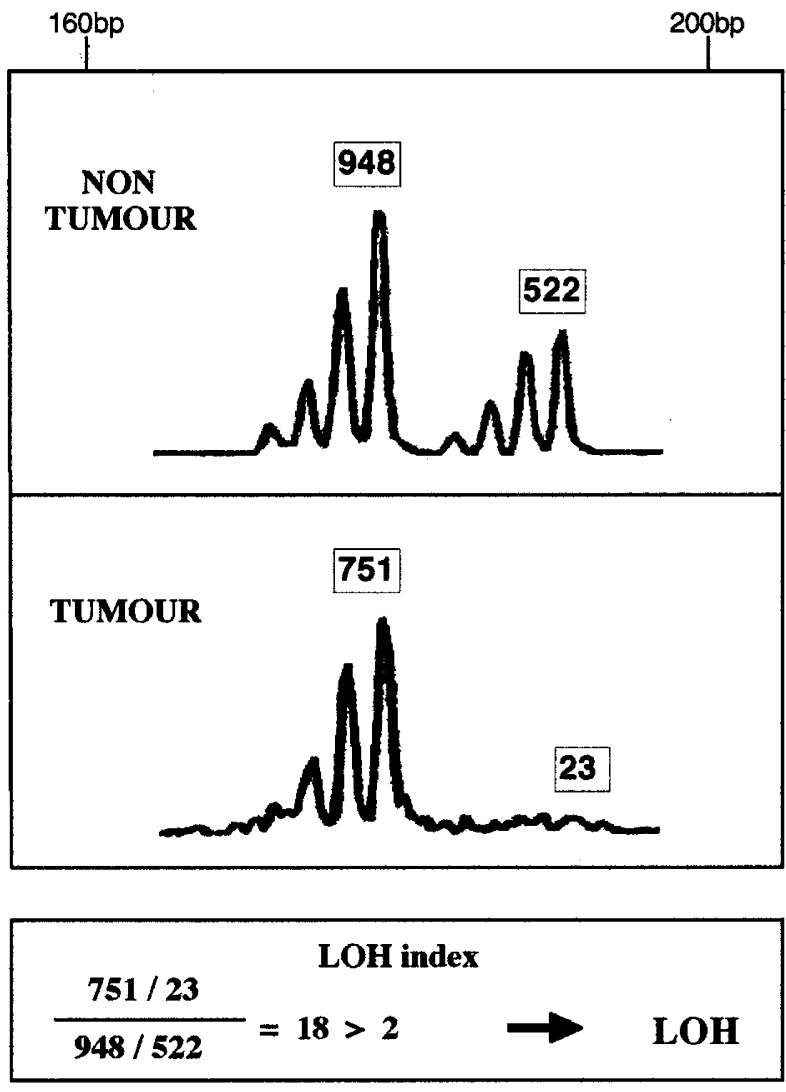

Figure 1 Example of LOH assessment at locus WFDC1-GT20. Upper trace, amplification from normal tissue; lower trace, amplification from tumour tissue. Alleles are automatically labelled with their peak height (in arbitrary units, in boxes). The LOH index is calculated as indicated.

\section{Mutation analysis}

PCR was performed in coding exons (exons 1 to 4 ) and their surrounding regions. Details of oligonucleotide sequences are summarized in Table 1. PCR reactions were carried out in a $50 \mu \mathrm{l}$ volume containing $0.5 \mu \mathrm{M}$ of each primer; $50 \mu \mathrm{M}$ of each dNTP; $2.5 \mu \mathrm{l}$ of formamide and $2 \mathrm{U}$ of Taq (Q.biogene, Illkirch, France) using a gene Amp PCR system 2400 (Applied Biosystems, Foster City, USA) and using the following conditions: (a) $94^{\circ} \mathrm{C}$ (4 min); (b) 40 cycles of $92^{\circ} \mathrm{C}(1 \mathrm{~min})$, $58^{\circ} \mathrm{C}(1 \mathrm{~min}), 72^{\circ} \mathrm{C}(1 \mathrm{~min})$; and (c) a final extension step at $72^{\circ} \mathrm{C}$ (7 min). Sequencing was performed on both strands using the ABI Prism dichloro-rhodamine terminator cycle sequencing ready reaction kit (Applied Biosystems, Foster City, USA) after purification of the PCR products using the Qiaquick PCR purification kit (Qiagen, Courtaboeuf, France). The sequences were analysed on an ABI 310 automated sequencer unit (Applied Biosystems, Foster City, USA).

\section{Analysis of methylation status}

To determine whether the WFDC1 presumptive promoter regions were hypermethylated, a PCR-based HpaII restriction enzyme assay was used. Two $\mu$ g of DNA was digested separately in a total volume of $20 \mu \mathrm{l}$ with either 20 units of $R s a \mathrm{I}$ or 20 units of RsaI and HpaII (Roche Diagnostics, Meylan, France) at $37^{\circ} \mathrm{C}$ for $16 \mathrm{~h}$. Another 2 units of each enzyme were added for an additional $1 \mathrm{~h}$ at $37^{\circ} \mathrm{C}$ to ensure complete digestion with the methylation-sensitive restriction endonucleases. Two $\mu \mathrm{l}$ of restricted DNA was then included in 2 PCR directed to the WFDC1 promoter containing two HpaII sites (sense primer: 5'CGAAATCTGAACAAGGTAGCAG-3'; antisense primer: 5'CTTGCTTGGAGACGTGGC-3') and to a reference sequence devoid of RsaI and HpaII sites located in exon 6 of the WFDC1 gene (sense primer: 5'-ACCAGGCTTCATTTGGCAGT-3'; antisense primer: 5'-TCCTCAACCTGGTGGTGAAAG-3'). PCR was performed by using an ABI PRISM 7700 Sequence Detector and SYBR Green reagents in the standard conditions recommended by the manufacturer (Applied Biosystems, Foster City, USA). For each PCR, a same standard curve was produced, using four 1 in 10 dilutions of a same non digest DNA. All samples were run in triplicate. The methylation index (\%) in a sample was calculated using the following equation:

$$
\text { Methylation index=RH }(\text { RsaI+HpaII }) / \mathrm{R}(\mathrm{RsaI}) \times 100 \%
$$

where $\mathrm{RH}$ is the quantity of methylated WFDC1 sequences measured following digestion by $R s a \mathrm{I}+H p a \mathrm{II}$ and $\mathrm{R}$ the results from the 'mock' digest without HpaII. The reference sequence in exon 6 was used to normalize the $\mathrm{RH}$ and $\mathrm{R}$ results. For each sample, a control where MspI, an enzyme insensitive to the methylation, replaced HpaII, showed full digestion.

\section{Expression of the WFDC1 gene}

WFDC1 gene expression was studied on total RNA extracted from $20 \mathrm{mg}$ tissue or $10^{6}$ cells from three independant primary culture of hepatocytes or cell lines with a QIAamp Tissue kit (Qiagen, Courtaboeuf, France) according to the manufacturer's instructions. cDNA synthesis was performed in a volume of $50 \mu \mathrm{l}$ using TaqMan reverse transcription reagents (Applied Biosystems, Foster City, USA). RT buffer $10 \times(5 \mu \mathrm{l}), 5 \mathrm{~mm} \mathrm{MgCl}_{2}, 500 \mu \mathrm{M}$ each dNTP, $2.5 \mu \mathrm{M}$ random hexamers, $20 \mathrm{U}$ Rnase inhibitor and $75 \mathrm{U}$ Multiscribe reverse transcriptase were mixed with $2.5 \mu \mathrm{g}$ of total RNA. The cycling conditions were $10 \mathrm{~min}$ at $25^{\circ} \mathrm{C}, 30 \mathrm{~min}$ at $48^{\circ} \mathrm{C}$, and 5 min incubation at $95^{\circ} \mathrm{C}$. PCR was performed by using an ABI PRISM 7700 Sequence Detector and SYBR Green reagents in the standard condition recommended by the manufacturer (Applied Biosystems, Foster City, USA) with two primers located on different exons (forward primer 5'-GCTATGAGTGCCACATCCTGAG-3' in exon 4; reverse primer 5'GTTGTCCCCTTCCAGGTTCTG-3' in exon 6). Taqman Ribosomal RNA Control Reagents (Applied Biosystems, Foster City, USA) designed to the Ribosomal S18 RNA amplification and primers designed to the $\beta$-actin gene amplification (forward primer 5'-AGCCTCGCCTTTGCCGA-3'; reverse primer 5'-GCGCGGCGATATCATCATC-3') were used as reference to normalize the results. 


\section{Results}

\section{LOH analysis}

Allele sizes in 50 DNA samples extracted from blood from unrelated European patients with hepatocellular carcinomas varied from 151 to $197 \mathrm{bp}$ for WFDC1-GT20 and from 204 to 212 bp for WFDC1-GT12. Heterozygosity was observed in 36 of 50 individuals (72\%) for WFDC1-GT20 and 21 of 50 individuals (42\%) for WFDC1-GT12. For the two polymorphisms combined, informativity was $86 \%$ among the 50 individuals analysed. DNAs from 46 hepatocellular carcinoma samples and from paired peripheral blood samples were subjected to PCR. Forty were informative. An example of $\mathrm{LOH}$ assessment is shown in Figure 1. We unequivocally identified $\mathrm{LOH}$ in the WFDC1 gene in 4/40 (10\%) of the informative hepatocellular tumour samples.

Of the five cell lines analysed, only the HepG2 cell line showed two distinct alleles indicative of the absence of $\mathrm{LOH}$.

\section{Mutation analysis}

In the aim to precise the role of WFDC1 in hepatocarcinogenesis, tumour samples from patients with $\mathrm{LOH}$ and cell lines were screened for mutation in the coding exons of the WFDC1 gene (exons 1 to 4 ). No nucleotide change resulting in amino acid change was detected.

\section{Promoter methylation analysis}

We further analysed the methylation status of the $5^{\prime}$ promoter region of the WFDC1 gene. Methylation status was classified as not significant $(<20 \%)$, partial $(20-80 \%)$ or full ( $>80 \%)$. Of the five cell lines analysed, two showed no significant WFDC1 promoter methylation and three exhib- ited partial methylation. In isolated hepatocytes the promoter was not significantly methylated (Table 2a). No significant difference in promoter methylation was neither observed between tumour samples and the corresponding non tumorous liver from patients exhibiting WFDC1 LOH in their tumour (Table 2b). In eight normal liver samples (obtained from donors during graft harvesting), promoter methylation was low (9\%, SD 8\%) (data not shown).

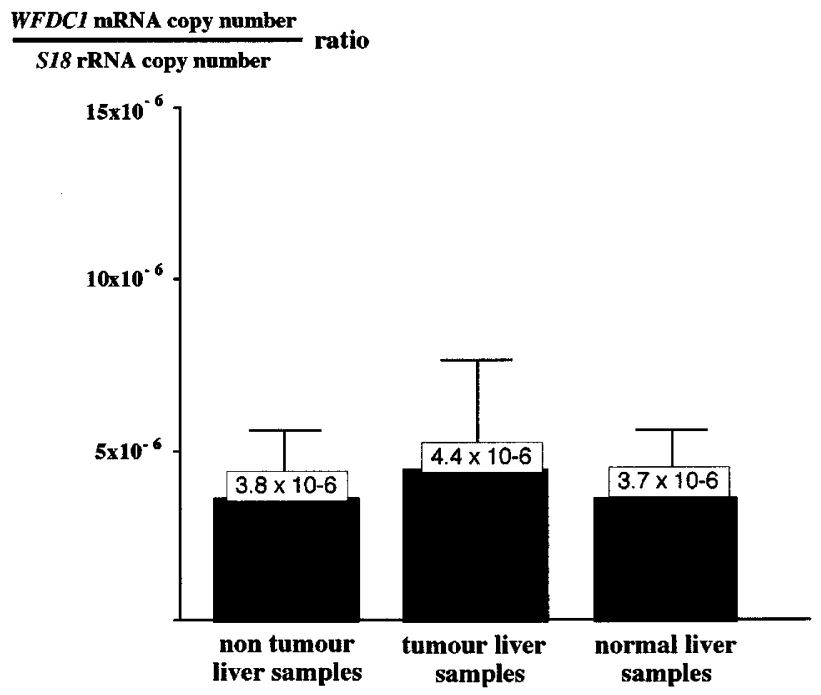

Figure 2 WFDC1 gene expression in $4 \mathrm{HCC}$ with $\mathrm{LOH}$, the corresponding non tumour samples and in eight normal livers.

Table 2a WFDC1 promoter methylation and gene expression in cell lines and isolated hepatocytes

\begin{tabular}{|c|c|c|c|c|}
\hline \multirow[b]{2}{*}{ Cell line } & \multicolumn{2}{|c|}{ Methylation } & \multicolumn{2}{|c|}{ Gene expression } \\
\hline & $\%$ & (SD) & $\left(\times 10^{-6}\right)$ & (SD) \\
\hline HA22TNGH & 7 & $(10)$ & 0.03 & $(0.01)$ \\
\hline HepG2 & 60 & (12) & 0 & $(0)$ \\
\hline $\mathrm{PLC} / \mathrm{PRF} / \mathrm{C}$ & 9 & (4) & 0.06 & $(0.03)$ \\
\hline MAHLAVU & 52 & (5) & 0.33 & $(0.20)$ \\
\hline TONG & 32 & (4) & 0.05 & $(0.01)$ \\
\hline Isolated hepatocytes & 2 & (2) & 0.18 & $(0.15)$ \\
\hline
\end{tabular}

Table 2b WFDC1 promoter methylation and gene expression (normalized to S18 RNA) in tumour and non-tumour samples from patients exhibiting $\mathrm{LOH}$ on the WFDC1 locus

\begin{tabular}{|c|c|c|c|c|c|c|c|c|c|c|}
\hline \multirow[b]{3}{*}{ Patient } & \multicolumn{5}{|c|}{ Non-tumour sample } & \multicolumn{5}{|c|}{ Tumour sample } \\
\hline & \multicolumn{2}{|c|}{ Methylation } & \multicolumn{2}{|c|}{ Gene expression } & \multirow[b]{2}{*}{$\mathrm{LOH}$} & \multicolumn{2}{|c|}{ Methylation } & \multicolumn{2}{|c|}{ Gene expression } & \multirow[b]{2}{*}{$\mathrm{LOH}$} \\
\hline & $\%$ & (SD) & $\left(\times 10^{-6}\right)$ & (SD) & & $\%$ & (SD) & $\left(\times 10^{-6}\right)$ & (SD) & \\
\hline Patient 1 & 1 & $(2)$ & 5.7 & $(1.2)$ & $(-)$ & 5 & (3) & 3.8 & (1.5) & $(+)$ \\
\hline Patient 2 & 7 & (2) & 3.0 & (1.5) & $(-)$ & 2 & (2) & 0.8 & $(0.5)$ & $(+)$ \\
\hline Patient 3 & 53 & (10) & 4.5 & (3.0) & $(-)$ & 38 & (9) & 8.2 & (2.6) & $(+)$ \\
\hline Patient 4 & 28 & (5) & 2.0 & (1.3) & $(-)$ & 25 & (7) & 4.9 & (2.1) & $(+)$ \\
\hline
\end{tabular}




\section{Analysis of WFDC1 gene expression in patients' samples and cell lines}

Gene expression was quantified in the four tumour samples exhibiting LOH comparatively to the four corresponding non tumour liver samples which were exempt of LOH (Table 2b). No significant up or down variation was observed between tumour, corresponding non tumour and normal liver samples ( $n=8$ ) (Figure 2 ). WFDC1 mRNA/ $\beta$-actin mRNA copy number ratio was $2.6 \times 10^{-4}\left(\mathrm{SD} 3 \times 10^{-4}\right)$ in normal liver samples. No significant difference was observed when $\beta$-actin was used to normalize the results (data not shown). In contrast, low level of gene expression was found in isolated hepatocytes preparations. Little or no gene expression was also found in hepatocellular carcinoma cell lines (Table 2a). Paradoxically, WFDC1 gene expression in MAHLAVU cell line was higher than that found in isolated hepatocytes although the level of its WFDC1 promoter methylation was higher. In HepG2 cell line where no expression of WFDC1 was observed, the two alleles of the genes were present and methylation of the promoter was similar to that of MAHLAVU.

\section{Discussion}

A high frequency of LOH has been observed on chromosome $16 \mathrm{q}(33-70 \%)$ in hepatocellular carcinoma. ${ }^{16}$ We report here $\mathrm{LOH}$ in the WFDC1 gene in 10\% of informative hepatocellular tumour samples. This low percentage can not be attributed to contamination of tumour DNA by DNA from non-tumourous cells since we selected samples containing more than $70 \%$ tumourous cells. These results suggest that $\mathrm{LOH}$ at the WFDC1 locus does not play a major part in European HCC.

Furthermore, absence of inactivating mutation of the WFDC1 gene in patients exhibiting $\mathrm{LOH}$ does not support a role of WFDC1 as a tumour suppressor gene.

Gene expression was observed in liver samples but no significant variation was observed between normal, non tumour and tumour samples. In contrast, little or no gene expression was found in isolated hepatocytes preparations and in hepatocellular carcinoma cell lines. These observations show that hepatocytes are not the main source of WFDC1 mRNA in liver.

DNA hypermethylation on $16 \mathrm{q}$ may be associated with $\mathrm{LOH}$ in HCC. ${ }^{17,18}$ In order to assess whether inactivation of WFDC1 could occur in hepatocytes via DNA methylation of the promoter region, DNA methylation of the $5^{\prime}$ sequences was measured. Absence or low level of DNA methylation was observed in tumour samples exhibiting $\mathrm{LOH}$ at the WFDC1 locus and partial DNA methylation (32-60\%) was observed in three hepatocellular carcinoma cell lines (HepG2, MAHLAVU and TONG) analysed. In HepG2, promoter methylation might contribute to the absence of expression of the gene although LOH is not observed. In MAHLAVU and TONG, mRNA expression did not seem related to promoter methylation.
In summary, we did not find frequent alterations of the WFDC1 gene in HCC. Taken together, these results are not in favour of a major role of WFDC1 as a tumour suppressor gene in this tumour type. However, we have described here a technique using two new microsatellite markers to identify $\mathrm{LOH}$ that is rapid and also informative for a large percentage of individuals. DNA promoter methylation analysis and sequencing of the WFDC1 gene are also described. As these assays are PCR-based, analysis of archival DNA is possible. Therefore, it may be used for retrospective analysis at the WFDC1 gene in paraffin-embedded tissue allowing investigation of both its tumour suppressor role and its prognostic value in other tumour types, preferentially in those known to show frequent 16q24 alterations.

\section{References}

1 Larsen M, Ressler SJ, Gerdes M et al: The WFDC1 gene encoding ps20 localizes to $16 \mathrm{q} 24$, a region of $\mathrm{LOH}$ in multiple cancers. Mamm Genome 2000; 11: 767-773.

2 Rowley DR, Tindall DJ: Responses of NBT-II bladder carcinoma cells to conditioned medium from normal fetal urogenital sinus. Cancer Res 1987; 47: 2955 - 2960.

3 Rowley DR: Characterization of a fetal urogenital sinus mesenchymal cell line U4F: secretion of a negative growth regulatory activity. In Vitro Cell Dev Biol 1992; 28A: 29-38.

4 Rowley DR, Dang TD, Larsen M, Gerdes MJ, McBride L, Lu B: Purification of a novel protein (ps20) from urogenital sinus mesenchymal cells with growth inhibitory properties in vitro. J Biol Chem 1995; 270: 22058-22065.

5 Larsen M, Ressler SJ, Lu B et al: Molecular cloning and expression of ps20 growth inhibitor. A novel WAP-type 'four-disulfide core' domain protein expressed in smooth muscle. J Biol Chem 1998; 273: $4574-4584$

6 Rowley DR: What might a stromal response mean to prostate cancer progression? Cancer Metastasis Rev 1998; 17: 411-419.

7 Salvucci M, Lemoine A, Saffroy R et al: Microsatellite instability in European hepatocellular carcinoma. Oncogene 1999; 18: 181 187.

8 Gramantieri L, Trere D, Pession A et al: Allelic imbalance on $16 \mathrm{q}$ in small, unifocal hepatocellular carcinoma: correlation with HBV and HCV infections and cellular proliferation rate. Dig Dis Sci 2000; 45: 306-311

9 Suzuki H, Komiya A, Emi M et al: Three distinct commonly deleted regions of chromosome arm 16q in human primary and metastatic prostate cancers. Genes Chromosomes Cancer 1996; 17: $225-233$.

10 Mason JE, Goodfellow PJ, Grundy PE, Skinner MA: 16q loss of heterozygosity and microsatellite instability in Wilms' tumor. J Pediatr Surg 2000; 35: 891-897.

11 Sato T, Akiyama F, Sakamoto G, Kasumi F, Nakamura Y: Accumulation of genetic alterations and progression of primary breast cancer. Cancer Res 1991; 51: 5794-5799.

12 Cleton-Jansen AM, Callen DF, Seshadri R et al: Loss of heterozygosity mapping at chromosome arm $16 \mathrm{q}$ in 712 breast tumors reveals factors that influence delineation of candidate regions. Cancer Res 2001; 61: 1171-1177.

13 Suzuki S, Moore DH, Ginzinger DG et al: An approach to analysis of large-scale correlations between genome changes and clinical endpoints in ovarian cancer. Cancer Res 2000; 60: 5382-5385.

14 Knudson Jr AG: Mutation and cancer: statistical study of retinoblastoma. Proc Natl Acad Sci USA 1971; 68: 820-823. 
15 Pichard L, Fabre I, Daujat M et al: Effect of corticosteroids on the expression of cytochromes $\mathrm{P} 450$ and on cyclosporin A oxidase activity in primary cultures of human hepatocytes. Mol Pharmacol 1992; 41: 1047-1055.

16 Kondoh N, Wakatsuki T, Hada A et al: Genetic and epigenetic events in human hepatocarcinogenesis (Review). Int J Oncol 2001; 18: $1271-1278$
17 Kanai Y, Ushijima S, Tsuda $\mathrm{H}$ et al: Aberrant DNA methylation on chromosome 16 is an early event in hepatocarcinogenesis. Jpn J Cancer Res 1996; 87: 1210-1217.

18 Kanai Y, Ushijima S, Tsuda $\mathrm{H}$ et al: Aberrant DNA methylation precedes loss of heterozygosity on chromosome 16 in chronic hepatitis and liver cirrhosis. Cancer letters 2000; 148: 73 -80. 